\title{
IMPROVED METHOD OF PURIFICATION OF Plum pox virus AND SEROLOGICAL ANALYSIS OF THE COAT PROTEIN
}

\section{A.A. SHEVELEVA, N.A. NIKITIN, E.A. TRIFONOVA, A.V. ZAKUBANSKIY, S.N. CHIRKOV}

M.V. Lomonosov Moscow State University, Department of Virology, Biological Faculty, 1/12, Leninskie gory, Moscow, 119234 Russia, e-mail s-chirkov1@yandex.ru

Acknowledgements:

Supported by Russian Science Foundation, grant № 14-24-00007

Received November 19, 2015

\section{Abstract}

Molecular weight heterogeneity of the coat protein (CP) is commonly observed in the purified potyvirus preparations due to partial proteolysis of the N-terminal domain exposed on the surface of viral particles. The cellular proteases released from disrupted plant tissues are believed to attribute to the partial CP proteolysis during purification and storage of the virus. The N-terminal domain is the most variable part of the CP. It displays virus- and strain-specific epitopes and is highly immunogenic. Degradation of the N-terminal domain creates a potential problem in the production of virus-specific antisera and strain-specific monoclonal antibodies and complicates the serological analysis of virus isolates. Plum pox virus (PPV) is considered the most important viral pathogen of stone fruit crops. Serological methods are of great importance for the diagnosis of PPV, strain identification, elaboration of PPV-resistant cultivars, epidemiological surveys and prevention of the uncontrolled spread of the virus in stone fruit plantings. The CP of PPV was studied by polyacrylamide gel electrophoresis, Western blotting and immunoelectron microscopy using monoclonal antibodies 5B and 4DG5 specific to the PPV universal and strain D epitopes, respectively. The purified virus particles have been shown to contain three types of subunits: full-size CP as well as the 28 and $31 \mathrm{kDa}$ products of its partial proteolysis. Three bands of the similar molecular weight were also detected in the analysis of fresh extracts from PPV- infected Nicotiana benthamiana tobacco leaves and a number of stone fruits (peach, plum and cherry plum), homogenized directly in the sample buffer, by Western blotting with the antibody 5B suggesting that the CP can be proteolytically processed already in infected plant tissues. The improved procedure of PPV purification, based on the combination of two original methods (H.J. van Oosten, 1972; S. Lain et al., 1988) has been developed. The procedure included accumulation of the virus in $N$. benthamiana plants, its extraction from the infected leaves using a neutral HEPES buffer, the incubation of the clarified extract with $5 \%$ Triton X-100, ultracentrifugation on a $20 \%$ sucrose cushion and purification of the virus using the ultracentrifugation in sucrose concentration gradient (10-40\%) in a $0.1 \mathrm{M}$ sodium borate buffer, pH 8.2. The method provided the yield up to $10 \mathrm{mg}$ of the purified virus from $100 \mathrm{~g}$ of infected leaves. The virus particles contained mainly the full-size CP. The high yield of the virus seems to be due to an effective extraction of the virus using HEPES buffer as well as its negligible losses during clarification of the extract, treatment with Triton X-100 and ultracentrifugation on a sucrose cushion. The use of Triton X-100 in the specified concentration leads to a more complete separation of the virus from membrane complexes and solubilization of aggregates of viral particles, that increases the yield of the virus. Application of such the virus preparations for animal immunization can facilitate the high specific antisera and monoclonal antibodies production for reliable detection and serological analysis of PPV.

Keywords: plum pox virus, purification, coat protein, Western blot, immunoelectron microscopy, monoclonal antibody, epitope

Plum pox virus (Plum pox virus, PPV, genus Potyvirus, family Potyviridae) is considered the most important viral pathogen of stone fruit crops [1, 2]. Filamentous virion consists of a 9.8 thousand nucleotides genomic RNA molecule and 2 thousand molecules of coat protein (CP) with a molecular weight of about $36.5 \mathrm{kDa}$, calculated by amino acid composition [3]. PPV systemically infects cultivated and wild Prunus plants, and many herbaceous species from other genera [4-8]. In the experiments, in particular for accumulating and preparative iso- 
lation of PPV, various tobacco species are used [9, 10].

Potyvirus CP consists of $\mathrm{N}$-terminal, core, and C-terminal domains. The unordered $\mathrm{N}$-domain is exposed on the surface of the virus particle. It contains viral and strain specific epitopes and is the most mutable portion of the molecule [11]. In potivirus preparations, $\mathrm{CP}$ is usually heterogeneous in molecular weight due to the $\mathrm{N}$-terminal domain partial proteolysis by plant proteases [12]. Two to three protein bands are identified in purified PPV preparations by polyacrylamide gel electrophoresis. The major band with a molecular weight of 35-43 kDa corresponds to the full-size CP. Differences in molecular weight are determined by the strain of viral isolates, the presence of deletions and appear to depend on the level of post-translational CP modifications as a result of its phosphorylation and/or glycosylation [13-15]. Minor bands with greater electrophoretic mobility are formed by the cleavage of various length peptides from CP N-terminus $[10,16]$.

Immunodominant CP N-terminal degradation complicates obtaining virus-specific antisera, the strain specific monoclonal antibodies, and immunochemical analysis of viral isolates [17]. However, serological methods are of great importance for the diagnosis of PPV, its strain identification, obtaining PPVresistant cultivars, and for epidemiological surveys and prevention of the uncontrolled spread of the virus in stone fruit plantings.

Our objective was to improve the procedure of plum pox virus (PPV) preparative isolation to produce highly purified virus containing full-size CPs predominantly at high yield. We have also conducted PPV CP proteolysis analysis using monoclonal antibodies with known specificity.

Technique. PPV-NAT virus isolate (GenBank accession number NC_001445) strain D was kindly provided by E. Maiss [18] and accumulated in Nicotiana benthamiana plants.

Infected mosaic leaves were collected 3-4 weeks after inoculation and used for virus isolation. Fresh leaves were homogenized manually in $0.02 \mathrm{M}$ HEPES buffer ( $\mathrm{pH}$ 6.8) containing $0.2 \mathrm{M}$ sucrose and $10 \mathrm{mM}$ sodium diethyldithiocarbamate at the sample:buffer ratio of 1:4 $(\mathrm{g} / \mathrm{ml})$. The extract was clarified in a J2-21 centrifuge (Beckman, USA) in a JA-20 rotor at $13000 \mathrm{rpm}$ and a temperature of $4{ }^{\circ} \mathrm{C}$ for 15 minutes and filtered through nonwoven Miracloth (Calbiochem, USA). Triton X-100 was added to the clarified extract with continuous stirring on a magnetic stirrer to a final concentration of $5 \%$ and mixed at $4{ }^{\circ} \mathrm{C}$ for 40 minutes more. The mixture was layered onto $20 \%$ (w/w) sucrose cushion in 0.02 M HEPES buffer ( $\mathrm{pH} \mathrm{6.8)}$ ) and centrifuged in an L5-50 ultracentrifuge (Beckman, USA) in an angularly $50.2 \mathrm{Ti}$ rotor at $28000 \mathrm{rpm}$ for 210 minutes. The pellet was resuspended in $0.1 \mathrm{M}$ sodium borate buffer $(\mathrm{pH}$ 8.2) containing $5 \mathrm{mM}$ EDTA.

Virus preparation was clarified in a MiniSpin tabletop centrifuge (Eppendorf, Germany) at 13,400 rpm for 5 minutes and purified by ultracentrifugation in a sucrose density gradient. For this purpose, virus suspension was layered onto preformed sucrose gradient (10-40\%, w/w) prepared in $0.1 \mathrm{M}$ sodium borate buffer ( $\mathrm{pH} 8.2$ ), and centrifuged in a SW 27 rotor at 25,000 rpm for 120 minutes. The contents of the tubes was fractionated using Auto DensiFlow IIC (Haakebuchler, USA) and Uvicord S (LKB, Sweden), collecting $2 \mathrm{ml}$ fractions. The fractions containing the greatest amount of virus were pooled and dialyzed against $0.05 \mathrm{M}$ borate buffer $(\mathrm{pH}$ 8.2) over night. Virus was pelleted by centrifugation in a $50.2 \mathrm{Ti}$ rotor at $30,000 \mathrm{rpm}$ for 150 minutes. The pellet was resuspended in $0.05 \mathrm{M}$ borate buffer $(\mathrm{pH} \mathrm{8.2)}$. At all stages of purification the virus content was measured by semi-quantitative enzyme immunoas- 
say using Reagent Set SRA 31505 kits (Agdia, USA). Virus concentration in the purified preparation was measured spectrophotometrically using extinction coefficient $\mathrm{A}_{260}(1 \mathrm{mg} / \mathrm{ml})=2.5[16]$.

Analysis of virus preparation and extracts from the leaves of infected plants was performed using polyacrylamide gel electrophoresis with sodium dodecyl sulfate (SDS) and Western blotting with 5B and 4DG5 monoclonal antibodies as previously described [15]. K10B and K12B kits were the source of antibodies (Agritest, Italy). The discovered and characterized by us PPV strain D isolates Cr11 (KR028385), Kobr8 (KP198590), and Pav6a (KP198596) from peach (Prunus persica), plum $(P$. domestica), and cherry plum ( $P$. cerasifera), respectively, were also used [19]. Virus preparation immunoelectron microscopy was performed as previously described [20] using primary antibodies $5 \mathrm{~B}$ at a dilution of 1:200 and secondary antibodies conjugated to $6 \mathrm{~nm}$ diameter colloidal gold particles (Jackson ImmunoResearch, Inc., USA) diluted 1:50. Samples were contrast-enhanced with $2 \%$ uranyl acetate and analyzed using a JEM-1400 electron microscope (JEOL, Japan). Images were obtained using Olympus Soft Imaging Solutions GmbH software (Germany).

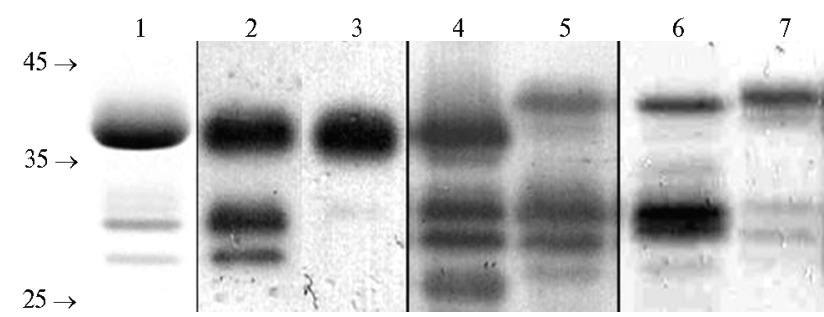

Fig. 1. Result of Plum pox virus analysis by $12 \%$ polyacrylamide gel electrophoresis and Western blotting: 1, 2, and $3-$ purified virus preparation (staining with Coomassie Brilliant Blue, 5B and 4DG5 monoclonal antibodies in Western blot test, respectively); 4, 5, 6, 7 - extracts of infected tobacco (Nicotiana benthamiana), cherry plum (Prunus cerasifera), peach $(P$. persica), and plum $(P$. domestica) leaves, respectively (staining with $5 \mathrm{~B}$ antibodies in Western blot). The positions of molecular weight markers, $\mathrm{kDa}$ (Fermentas, Lithuania) are indicated on the left. of the virus seems to be due to an effective extraction of the virus using HEPES buffer as well as its negligible losses in extract clarification, treatment with Triton X-100 and ultracentrifugation on sucrose cushion (data not shown). The use of high Triton X-100 concentrations (5\%) promotes more complete virus isolation from membrane complexes and solubilization of aggregates of viral particles, which increases the virus yield.

Three bands were detected in PPV purified preparation electrophoresis in polyacrylamide gel (Fig. 1, path 1). The major band seemingly represented a full-size CP and the minor 31 and $28 \mathrm{kDa}$ bands represented the products of its partial proteolysis $[10,16]$. Obvious full-size CP band prevalence indicated its low degradation which makes it possible to use such a virus preparation to obtain antisera and antivirus monoclonal antibodies.

Immunochemical $\mathrm{CP}$ analysis was performed using 5B and 4DG5 antibodies recognizing the universal epitope (expressed in most PPV isolates) and the epitope specific of strain D, respectively [21]. Universal epitope ${ }^{94} \mathrm{DRDVDAG}^{100}$ is located at the beginning of the core domain [22]. In Western blotting, antibodies 5B stained all protein bands detected in the purified virus preparation, that is they belonged to CPs (Fig. 1, path 2). Immunoelectron microscopy 


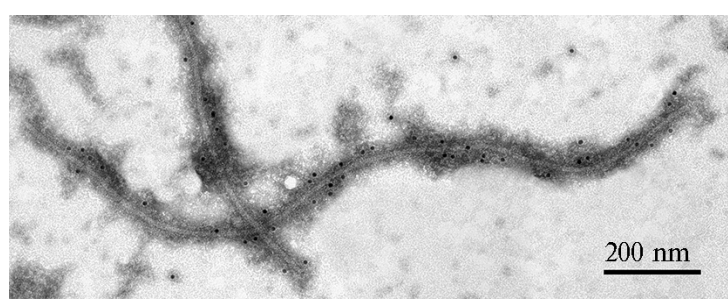

Fig. 2. Immunoelectron microscopy of Plum pox virus isolated from tobacco (Nicotiana benthamiana) leaves using primary antibodies $5 \mathrm{~B}$ and secondary antibodies conjugated to colloidal gold (6 $\mathbf{~ n m ) ~ ( 2 \% ~ u r a n y l ~ a c e t a t e ~}$ contrast enhancement; instrumental magnification of $\times 20000$, electron microscope JEM-1400, JEOL, Japan). demonstrated that anti-universal epitope antibodies bound intact CPs along the entire length of the viral particle (Fig. 2). 4DG5 antibodies recognize epitopes in the ${ }^{49}$ FTPATTQPATKPVS ${ }^{62}$ sequence typical of strain D isolates [22, 23]. They reacted with full-size CPs, but did not detect $28 \mathrm{kDa}$ polypeptides (Fig. 1, path 3) which were CPs lacking $70 \mathrm{~N}$-terminal amino acids. Since the site of proteolysis is located between glutamine $(\mathrm{Q})$ and threonine $(\mathrm{T})$ residues at positions 70 and 71, respectively [10], the $28 \mathrm{kDa}$ polypeptide did not contain the epitope recognized by antibodies 4DG5. Furthermore, 4DG5 antibodies reacted with the $31 \mathrm{kDa}$ polypeptide weakly (Fig. 1, path 3 ). The intermediate product of $33 \mathrm{kDa}$ proteolysis obtained by the treatment of purified isolate 5.15 (L42473) preparation with trypsin was clearly stained with 4DG5 antibodies [17]. The PPV-D-specific epitope was probably preserved in the $33 \mathrm{kDa}$ polypeptide but damaged in a shorter $31 \mathrm{kD}$ product. The differences in the molecular weight of the products formed may be due to different substrate specificities of trypsin and protease responsible for $\mathrm{CP}$ $\mathrm{N}$-terminal proteolysis in NAT isolate.

It is considered that $\mathrm{CP} \mathrm{N}$-terminal degradation occurs during preparative separation and storage of the virus and is due to cellular proteases that are released in homogenizing vegetative tissues and contaminate the purified preparation [12]. However, the three PPV CP bands of the similar or close molecular weight were regularly detected in Western blotting in the analysis of fresh extracts from infected leaves homogenized directly in the sample buffer. Thus, 5B antibody staining of all three bands was observed in the extracts from the leaves of $N$. benthamiana, plum, cherry plum, and peach infected with strain D (Fig. 1, paths 4-7). Furthermore, in samples 4-7, antibodies 5B stained another CP molecule fragment with a molecular weight of about $26 \mathrm{kDa}$. No staining was found in the extracts of non-infected leaves (data not shown). Similar staining of several PPV CP bands was observed in the analysis of extracts from the leaves of $N$. benthamiana и Canadian plum ( $P$. nigra) infected with strain W isolate 1410 [24]. Thus, our data suggest that CP proteolysis could take place directly in infected cells. This possibility is also indicated by the results of preparative PPV isolation using protease inhibitors. CP proteolysis products, although to a lesser extent, are also identified in virus preparations purified with inhiditors [16, 17]. It is worth noting that mobility of 31 and $28 \mathrm{kDa}$ bands was similar for all isolates and host plants, suggesting high CP proteolysis specificity. High electrophoretic mobility of intact PPV CP in the purified preparation and a sample of $N$. benthamiana was probably due to a deletion of 15 amino acids in NAT isolate [18).

It is not inconceivable that CP proteolysis involves not only cell-, but also virus-specific proteases [10]. Protyvirus genomic RNA in an infected cell is known to be translated to produce a polyprotein which is cut by three virusspecific proteases ( $\mathrm{P} 1, \mathrm{HcPro}$, and NIA) into 10 to 11 proteins, including $\mathrm{CP}$ [3]. Dipeptide ${ }^{70} \mathrm{QT}^{71}$ can be a substrate for NIa virus-specific protease in PPV [25] and a number of other potyviruses [26]. In this study, it was found in all isolates studied (Fig. 3), which would explain the origin of $28 \mathrm{kDa}$ polypeptide. 
Proteolysis site location resulted in $31 \mathrm{kDa}$ polypeptide is to be studied.

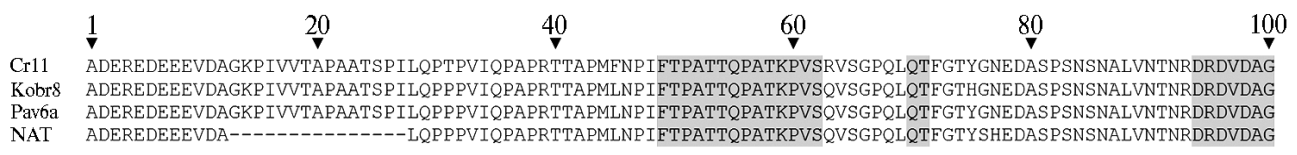

Fig. 3. Alignment of CP N-terminal amino acid sequences in Plum pox virus isolates. The sequences of D-specific epitope, dipeptide QT, and universal epitope are darkened. A series of dashes in the NAT sequence means a deletion of 15 amino acids. The numbers above alignment show the amino acid position in the sequence.

Thus, the method of plum pox virus (the PPV) preparative isolation provides a high yield of purified virus containing full-length coat protein $(\mathrm{CP})$ predominantly. Application of such virus preparations for animal immunization may facilitate high specific antisera and monoclonal antibodies production for diagnosis and serological analysis of PPV isolates. Analysis of PPV CP proteolysis products using $\mathrm{N}$-terminal epitope-specific monoclonal antibodies demonstrated that proteolysis may take place directly in infected cells

\section{REFEREN C ES}

1. Cambra M., B os c i a D., Myrta A., Llace r G. Plum pox virus and estimated cost associated with Sharka disease. EPPO Bull., 2006, 36: 202-204 (doi: 10.1111/j.13652338.2006.01027.x).

2. Chirkov S.N., Prikhod'ko Yu.N. Geneticheskoe raznoobrazie i struktura populyatsii virusa ospy (sharki) slivy v Rossii [Genetic diversity and population structure of Plum pox virus in Russia]. Sel'skokhozyaistvennaya Biologiya [Agricultural Biology], 2015, 50(5): 529-539 (doi: 10.15389/agrobiology.2015.5.529rus, 10.15389/agrobiology.2015.5.529eng).

3. Garcia J.A., Glas a M., Cambra M., Candresse T. Plum pox virus and sharka: a model potyvirus and a major disease. Mol. Plant Pathol., 2014, 15: 226-241 (doi: 10.1111/mpp.12083).

4. L la ce r G., C a mbra M. Host and symptoms of Plum pox virus: fruiting Prunus species. EPPO Bull., 2006, 36: 219-221 (doi: 10.1111/j.1365-2338.2006.00975.x).

5. J a m e s D., Thompson D. Host and symptoms of Plum pox virus: ornamental and wild Prunus species. EPPO Bull., 2006, 36: 222-224 (doi: 10.1111/j.1365-2338.2006.00976.x).

6. P o l a k J. Host and symptoms of Plum pox virus: woody species other than fruit and ornamental species of Prunus. EPPO Bull., 2006, 36: 225-226 (doi: 10.1111/j.1365-2338.2006.00977.x).

7. L l a c e r G. Host and symptoms of Plum pox virus: herbaceous hosts. EPPO Bull., 2006, 36: 227-228 (doi: 10.1111/j.1365-2338.2006.00978.x).

8. va n O o st e n H.J. Herbaceous host plants for the sharka (plum pox) virus. Neth. J. Pl. Path., 1970, 76: 253-260 (doi: 10.1007/BF01976584).

9. van O osten H.J. Purification of plum pox (sharka) virus with the use of Triton X-100. Neth. J. Pl. Path., 1972, 78: 33-44 (doi: 10.1007/BF02077555).

10. Laín S., Ri e chmann J.L., M éndez E., Ga r cía J.A. Nucleotide sequence of the 3' terminal region of plum pox potyvirus RNA. Virus Res., 1988, 10: 325-341 (doi: 10.1016/01681702(88)90074-3).

11. Shukla D.D., Jilka J., Tosic M., Ford R.E. A novel approach to the serology of potyviruses involving affinity-purified polyclonal antibodies directed towards virus-specific $\mathrm{N}$ termini of coat protein. J. Gen. Virol., 1989, 70: 13-23 (doi: 10.1099/0022-1317-70-1-13).

12. Shukla D.D., Strike P.M., Tracy S.L., Gough K.H., Ward C.W. The N and C termini of the coat proteins of potyviruses are surface-located and the $\mathrm{N}$ terminus contains the major virus-specific epitopes. J. Gen. Virol., 1988, 69: 1497-1508 (doi: 10.1099/00221317-69-7-1497).

13. S u b r Z., G las a M. Plum pox virus variability detected by the advanced analytical methods. Acta Virologica, 2008, 52: 75-90.

14. Kolle rova E., Glas a M., Subr Z.W. Western blotting analysis of the Plum pox virus capsid protein. J. Plant Pathol., 2008, 90: S1.19-S1.22 (doi: 10.4454/jpp.v90i1sup.610).

15. S heveleva A., I va nov P., Pri hodko Y., J a mes D., C hi rkov S. Occurrence and genetic diversity of Winona-like Plum pox virus isolates in Russia. Plant Dis., 2012, 96: 11351142 (doi: 10.1094/PDIS-12-11-1045-RE).

16. Lopez-Moya J.J., Canto T., Lo pez-Abella D., Diaz-Ruiz J.R. Differentiation of Mediterranean plum pox virus isolates by coat protein analysis. Plant Pathol., 1994, 43: 164-171 (doi: 10.1111/j.1365-3059.1994.tb00566.x). 
17. Lopez-Moya J.J., Sanz A., Cambra M., Gorris M.T., Anaya C., Miguet J.G., Cortes E., Lopez-Abella D. Production and characterization of monoclonal antibodies to plum pox virus and their use in differentiation of Mediterranean isolates. Arch. Virol., 1994, 135: 293-304 (doi: 10.1007/BF01310015).

18. Maiss E., Timpe U., B risske A., Jelkman W., C asper R., Himmle r G., $\mathrm{M}$ att a novich D., Katti nge r H.W. The complete nucleotide sequence of plum pox virus RNA. J. Gen. Virol., 1989, 70: 513-524 (doi: 10.1099/0022-1317-70-3-513).

19. Chirkov S., Ivanov P., Sheveleva A., Kudryavtseva A., Prikhodko Y., Mitrofanova I. Occurrence and characterization of Plum pox virus strain D isolates from European Russia and Crimea. Arch. Virol., 2016, 161: 425-430 (doi: 10.1007/s00705-015-2658-x).

20. Nikitin N., Trifonova E., Karpova O., At abekov J. Examination of biologically active nanocomplexes by nanoparticle tracking analysis. Microsc. Microanal., 2013, 19: 808-813 (doi: 10.1017/S1431927613000597).

21. Cambra M., As ensio M., Gorris M.T., Perez E., Camarasa E., Garcia J.A., Moy a J.J., Lopez-Abella D., Ve la C., S a nz A. Detection of plum pox potyvirus using monoclonal antibodies to structural and non-structural proteins. EPPO Bull., 1994, 24: 569577 (doi: 10.1111/j.1365-2338.1994.tb01070.x).

22. Candresse T., S a e nz P., Garcia J.A., Boscia D., Navratil M., Gorris M.T., $\mathrm{C}$ a mb a M. Analysis of the epitope structure of Plum pox virus coat protein. Phytopathology, 2011, 101: 611-619 (doi: 10.1094/PHYTO-10-10-0274).

23. Candresse T., C a mbra M., Da 11 ot S., Lanneau M., Asensio M., Gorris M.T., Revers F., Macquaire G., O $1 \mathrm{mos}$ A., Boscia D., Quiot J.B., $\mathrm{D} \mathrm{u}$ ne z J. Comparison of monoclonal antibodies and polymerase chain reaction assays for the typing of isolates belonging to the $\mathrm{D}$ and $\mathrm{M}$ serotypes of plum pox potyvirus. Phytopathology, 1998, 88(3): 198-204 (doi: 10.1094/PHYTO.1998.88.3.198).

24. Sheveleva A., Chirkov S., Nemova E. Detection of a new Winona-like Plum pox virus isolate in naturally infected Canadian plum (Prunus nigra) in Russia. Acta Horticulturae, 2011, 899: 49-55 (doi: 10.17660/ActaHortic.2011.899.5).

25. G a r cia J.A., Martin M.T., C e rvera M.T., Rei ch man n J.L. Proteolytic processing of the plum pox virus polyprotein by the NIa protease at a novel cleavage site. Virology, 1992, 188: 697-703 (doi: 10.1016/0042-6822(92)90524-S).

26. A d a m s M.J., A n t o n i w J.F., B e a u d o i n F. Overview and analysis of the polyprotein cleavage sites in the family Potyviridae. Mol. Plant Pathol., 2005, 6: 471-487 (doi: 10.1111/J.1364-3703.2005.00296.X).

\section{$6^{\text {th }}$ EUROPEAN CONGRESS OF VIROLOGY (ECV2016)}

(19-22 October 2016, Hamburg, Germany)

Organization: European Society for Virology, Heinrich Pette Institute

The European Congress of Virology is the premier virology conference in Europe and is organized by the European Society for Virology (ESV). ECV2016 will bring together both junior and senior scientists, and will cover all aspects of virus research including basic, clinical, veterinary and plant virology.

The science, the planned special events, and the city itself will make ECV2016 a highly stimulating and unforgettable international event that should not be missed.

Information: http://www.globaleventslist.elsevier.com/events/2016/10/6th-european-congress-of-virology/ 